\title{
Mild Traumatic Brain Injury: Are ED Providers Identifying Which Patients Are at Risk?
}

\author{
Barbara Stuart \\ Brigham Young University - Provo \\ Barbara Mandleco \\ Brigham Young University - Provo \\ Renea L. Beckstrand \\ Brigham Young University - Provo, renea@byu.edu \\ Sondra Heaston \\ Brigham Young University - Provo
}

Follow this and additional works at: https://scholarsarchive.byu.edu/facpub

Part of the Other Nursing Commons

\section{Original Publication Citation}

Stewart, B., Mandleco, B., Wilshaw, R., \& Beckstrand, R. L. (2012). Mild traumatic brain injury: Are ED providers identifying which patients are at risk? Journal of Emergency Nursing (39)5, pp 435-442.

\section{BYU ScholarsArchive Citation}

Stuart, Barbara; Mandleco, Barbara; Beckstrand, Renea L.; and Heaston, Sondra, "Mild Traumatic Brain Injury: Are ED Providers Identifying Which Patients Are at Risk?" (2011). Faculty Publications. 5314. https://scholarsarchive.byu.edu/facpub/5314 accepted for inclusion in Faculty Publications by an authorized administrator of BYU ScholarsArchive. For more information, please contact ellen_amatangelo@byu.edu. 


\section{Mild Traumatic Brain Injury: Are ED Providers Identifying Which Patients ARE AT RISK?}

Authors: Barbara Stuart, MS, APRN, NP-C, CEN, Barbara Mandleco, PhD, RN, Russell Wilshaw, MS, RN, Renea L. Beckstrand, PhD, RN, CCRN, CNE, and Sondra Heaston, MS, APRN, NP-C, CEN, Provo and Salt Lake City, UT

\section{CE Earn Up to 10 CE Hours. See page 504.}

Objective: To identify patients with specific ED discharge diagnoses reporting symptoms associated with a mild traumatic brain injury (MTBI), compare frequency/severity of MTBI symptoms by discharge diagnosis, investigate head injury education provided at ED discharge, and learn about changes made by MTBI patients after injury.

Methods: The Post Concussion Symptom Scale, a demographic questionnaire, and open-ended questions about the impact the injury had on patients' lives were completed by 52 ED patients, at least 2 weeks after injury, discharged with concussion/closed head injury, head laceration, motor vehicle crash (MVC), or whiplash/cervical strain diagnoses.

Results: Between 1 and 23 MTBI symptoms were reported by $84.6 \%$ of the participants. Headache and fatigue were the most common; female patients had almost twice as many symptoms on average as male patients. Of MVC patients, 83.3\% reported moderate severity scores for all 4 Post Concussion Symptom Scale categories, and these represented the highest overall severity scores. Concussion/closed head injury diagnosis patients received the most head injury education. The majority of patients were more cautious after injury.

Conclusion: Most participants reported having MTBI symptoms. Although MVC participants reported the most severe MTBI symptoms, they had the least head injury education. Emergency nurses need to be aware patients may have an MTBI regardless of their presenting symptoms or injury severity.

Key words: MTBI; Head injury; Concussion; Post-concussive syndrome
Barbara Stuart, President, Utah State ENA, and Member, Timpanogos Chapter, is Staff Nurse, Emergency Department, Utah Valley Regional Medical Center, Provo, UT.

Barbara Mandleco is Professor, Brigham Young University College of Nursing, Provo, UT.

Russell Wilshaw is Trauma Outreach \& Injury Prevention Coordinator, University of Utah Health Care, Salt Lake City, UT.

Renea L. Beckstrand, Member, Timpanogos Chapter, Utah State ENA, is Associate Professor, Brigham Young University College of Nursing, Provo, UT.

Sondra Heaston, Member, Timpanogos Chapter, Utah State ENA, is Assistant Teaching Professor, Brigham Young University College of Nursing, Provo, UT.

This project was funded by a Brigham Young University Graduate Studies research grant.

For correspondence, write: Barbara Mandleco, RN, PhD, Brigham Young University College of Nursing, 474 SWKT, Provo, UT 84602; E-mail: barbara_mandleco@byu.edu.

J Emerg Nurs 2012;38:435-42.

Available online 19 July 2011.

$0099-1767 / \$ 36.00$

Copyright (C) 2012 Emergency Nurses Association. Published by Elsevier Inc. All rights reserved.

doi: $10.1016 /$ j.jen.2011.04.006
$\mathrm{M}$ ild traumatic brain injury (MTBI), commonly referred to as a concussion, is defined as a blow or jolt to the head or a penetrating head injury that disrupts brain functioning, according to the Centers for Disease Control and Prevention (CDC). ${ }^{1}$ However, in a comprehensive report from the World Health Organization Collaborating Centre Task Force on Mild Traumatic Brain Injury, ${ }^{2}$ the definition was expanded to include acute brain injuries resulting from mechanical energy to the head from an external physical force. Criteria for clinical identification of an MTBI consist of 1 or more of the following: confusion or disorientation, loss of consciousness (LOC) for 30 minutes or less, post-traumatic amnesia for less than 24 hours and/or other transient neurologic abnormalities, and a Glasgow Coma Scale score of 13 to 15 for a time frame up to 30 minutes after injury that are not due to drugs, alcohol, medications, or other injuries/treatment for other injuries. ${ }^{2}$ However, despite this definition, emergency clinicians have difficulty identifying MTBI patients because providers tend to rely heavily on a reported LOC to make the diagnosis. ${ }^{3}$ Conversely, patients with an MTBI may not have an LOC or the episode may have been so brief that they may not even know it occurred. ${ }^{4-6}$ 
Unfortunately, an MTBI can be anything but "mild" to the patient who suffers sequelae long after the initial injury and can lead to lifelong impairment affecting the ability to function physically, cognitively, and psychologically. ${ }^{7,8}$ Symptoms are best treated early with a multidisciplinary approach for optimal recovery, which makes timely recognition and diagnosis crucial. ${ }^{9,10}$ If left untreated, persistent MTBI symptoms frequently become worse and have a significant impact on quality of life. ${ }^{11,12}$ Therefore the purpose of this pilot project was to investigate the frequency/severity of MTBI symptoms related to specific ED discharge diagnoses, identify the frequency and type of head injury education provided at the time of discharge, and identify how the injury has impacted patients' lives so that more appropriate interventions can be provided.

\section{Review of the Literature}

Nearly $90 \%$ of the more than 2 million annual traumatic brain injuries in the United States are classified as MTBIs. ${ }^{13}$ Interestingly, the CDC refers to MTBI as a "silent epidemic" because resulting problems are often not immediately apparent. ${ }^{14}$ In fact, after the MTBI, many patients are unable to return to work or function at a lower level than before the injury. ${ }^{13}$

Estimates indicate that emergency departments treat 100 to 300 head injuries per 100,000 population per annum, but only $56 \%$ of recognized MTBI cases (meeting $\mathrm{CDC}$ criteria for mild brain injury) were documented in the $\mathrm{ED}$ record as MTBI. ${ }^{3}$ In addition, the same investigators discovered that of patients who did report an LOC, only $72 \%$ had documentation of an MTBI in their ED record. More significantly, $94 \%$ of patients not diagnosed with MTBI reported being confused immediately after the injury. This is concerning because LOC and confusion are hallmark symptoms of MTBI and are objective findings practitioners can use to support a diagnosis of MTBI.

Several factors contribute to under diagnosis of MTBI. One factor is that many ED health care providers treating mildly injured patients may be unfamiliar with recent literature concerning MTBI. Second, ED providers are also more focused on identifying emergent conditions and not giving serious attention to largely subjective complaints that are common in patients with an unresolved MTBI. Third, using the term "mild" in describing any type of brain injury predisposes both provider and patient to minimize the injury. Finally, ED providers accustomed to evaluating severe head injuries may view mildly concussed patients as fortunate to have escaped serious brain damage and may discount the significance of a milder injury. ${ }^{15}$
Over the past 5 years, studies have focused on the benefits of early MTBI recognition followed by appropriate interventions. ${ }^{16-18}$ However, not much information is found in the literature related to the effects of early MTBI intervention for patients, even though evidence suggests promise for educational support and intervention when provided early after an injury. ${ }^{18}$

\section{Procedure}

After obtaining institutional review board approval, we indentified all patients seen in the emergency department of a 330-bed full-service tertiary facility during 1 calendar year who met the inclusion criteria (at least 2 weeks after ED presentation, aged between 18 and 28 years, with a discharge diagnosis of closed head injury [CHI]/concussion, head laceration, facial/jaw fracture, whiplash, cervical strain, motor vehicle crash [MVC], or multiple injuries) based on their electronic charts. These patients were contacted by a letter signed by the Medical Director of the Office of Research of the hospital's parent organization inviting them to participate by completing a survey available either online with Survey Monkey (Surveymonkey.com; Palo Alto, California) or as a hard copy by mail. Patients were excluded if they did not speak English, had previous health problems or a history of psychiatric illness, or were currently taking mood-altering, pain, or muscle relaxant medications. Upon completion of the survey, participants were paid $\$ 10$ cash.

\section{Measures}

Participants completed 3 measures: the Post Concussion Symptom Scale (PCSS), a demographic questionnaire, and a series of open-ended questions. The PCSS identifies common MTBI symptoms in 4 categories, as described by Schatz et $\mathrm{al}^{9}$ : - physical, thinking, sleep, and emotional. Each symptom was rated on a Likert scale from 0 to 6 , with 0 indicating none; 1 to 2 , mild; 3 to 4 , moderate; and 5 to 6 , severe. A mean severity score was calculated for each symptom and for each of the 4 symptom categories according to discharge diagnosis. The sensitivity for identifying an MTBI by use of the PCSS is $81.9 \%$, and the specificity is $89.4 \%$. The demographic questionnaire included age, gender, date of injury, mechanism of injury, ED discharge diagnosis, amount of time between injury and seeking medical care, years of education, employment or student status, amount of time taken off from work or school, whether any MTBI education was provided in the emergency department, and whether further health care was obtained after the ED visit. The open-ended questions asked participants to provide information about care received for their injury during and after their ED visit, the overall impact the injury has 
TABLE 1

Demographic data $(\mathrm{N}=52)$

\begin{tabular}{|c|c|c|c|c|}
\hline Variable & Mean (SD) & Frequency & $\begin{array}{l}\text { No. of symptoms } \\
\text { [mean (SD)] }\end{array}$ & $\begin{array}{l}<1 \text { wk off from } \\
\text { school/work }\end{array}$ \\
\hline Age (y) & $22.75(2.68)$ & & & \\
\hline Male & & $51 \%$ & $6.76(6.53)$ & \\
\hline Female & & $49 \%$ & $12.68(6.32)$ & \\
\hline Time since injury (mo) & $4(2.12)$ & & & \\
\hline$\geq 2 \mathrm{y}$ of college & & $55 \%$ & & \\
\hline Current student & & $75 \%$ & & $65 \%$ \\
\hline Employed part time & & $73 \%$ & & $71 \%$ \\
\hline Sought ED care on day of injury & & $92 \%$ & & \\
\hline
\end{tabular}

had on their life, and any changes they have made as a result of the injury.

\section{Data analysis}

Descriptive statistics for demographic data, individual PCSS symptoms, the 4 PCSS categories, PCSS symptoms according to discharge diagnosis, and whether head injury information was provided in the emergency department and, if provided, its format (oral, written, or both) were calculated by use of SPSS software (SPSS, Chicago, IL). Responses to the open-ended questions were reviewed for common themes according to qualitative methodology. ${ }^{19}$ Responses were compared across participants, and direct quotes that best reflected each category were then chosen.

\section{Results}

Table 1 shows sample demographic data. Upon analysis of the PCSS, 9 participants (17.3\%) reported no symptoms after their initial ED visit. However, the remainder $(82.7 \%)$ reported having from 1 to 23 different symptoms, with a mean of 9.57 symptoms each. Table 2 shows more information about participant symptoms.

Mean severity scores (mild, 1-2; moderate, 3-4; or severe, 5-6) for the 4 categories of symptoms within each discharge diagnosis are found in Table 3.

Table 4 presents information on education received upon discharge according to discharge diagnosis.

Of the respondents, 13 (25\%) indicated they had not made any changes in their lives since the injury. Analysis of answers by those who did report changes showed 3 main themes: health/functioning, psychological, and social/economic. Many respondents wrote multiple comments that could be placed in more than 1 theme. The health/functioning theme (30.3\%) included physical symptoms (52\%) such as headaches and fatigue or neurologic and sensory difficulties $(21.7 \%)$. However, some fell into both categories (26.1\%). Comments related to physical symptoms were "I am more tired than usual" and "I never used to have headaches and now I have them frequently." Comments related to neurologic/sensory difficulties included that the patient found it "hard to focus, concentrate, and remember things."

The psychological theme (48.7\%) was further divided into 2 subthemes: neuropsychological (30.6\%), representing thought and emotional processes, such as feeling nervous, irritable, anxious, or fearful, and neurobehavioral (70.3\%), which represented changes in physical behaviors such as wearing a helmet or avoiding specific activities as a result of the injury. Examples of comments placed into the neuropsychological subtheme were "I feel almost worthless" and "I feel numb now." The neurobehavioral subtheme included comments such as "I will always wear a helmet when riding a bike" and "overall, I am more cautious."

The social and economic theme $(21.1 \%)$ reflected statements about changes in societal roles, relationships, and/or finances; $62.5 \%$ of the responses in this theme involved a change in the ability to work or attend college, and $12.5 \%$ made a comment about increased difficulty with finances. Relationship issues represented 25\%, with statements such as "I broke up with my boyfriend." Other comments were "I had to leave my job and withdraw from college" (role in society/finances) and "I struggle in school" (role in society).

\section{Discussion}

The most common symptoms participants reported were headache, fatigue, difficulty remembering and concentrating, trouble falling asleep, and irritability. These findings are consistent with previous research identifying similar complaints. ${ }^{4,20}$ In fact, the rate of headache has been reported as high as $90 \%$ after initial injury and was still 
TABLE 2

Mean severity score by discharge diagnosis and symptom category

\begin{tabular}{|c|c|c|c|c|c|}
\hline \multirow[t]{2}{*}{ Diagnosis } & \multirow[t]{2}{*}{$\mathbf{n}$} & \multicolumn{4}{|c|}{ Mean (SD) } \\
\hline & & Physical & Thinking & Sleep & Emotional \\
\hline Concussion & 27 & $1.96(0.39)$ & $2.20(0.59)$ & $2.43(0.38)$ & $1.74(0.47)$ \\
\hline Head laceration & 16 & $1.75(0.94)$ & $1.56(0.63)$ & $2.38(1.31)$ & $1.65(0.47)$ \\
\hline MVC & 12 & $2.98(0.50)$ & $2.81(0.77)$ & $2.99(0.66)$ & $3.37(0.34)$ \\
\hline Whiplash & 7 & $2.92(0.45)$ & $3.31(0.68)$ & $2.71(0.57)$ & $2.50(0.49)$ \\
\hline
\end{tabular}

present at 6 months in 44\% of MTBI patients. ${ }^{21}$ The same authors reported that fatigue and sleep disturbance were among the most common symptoms reported between 1 and 3 months after injury and difficulty with attention and memory were the most difficult during the first month after injury. Six months after injury, many complaints had diminished, although some patients still reported headache, dizziness, and drowsiness. ${ }^{20,22}$

This study also discovered that female participants had almost twice as many symptoms (12.68) as male participants (6.76). This information is similar to other research $^{23-26}$ and a meta-analysis of gender differences in traumatic brain injury outcomes, ${ }^{27}$ which found that women reported more postconcussive symptoms, including headache, impaired memory, dizziness, irritability, insomnia, double vision, and impaired concentration, than men. Our findings, however, are different from other research, which discovered that women are less likely to report postconcussive symptoms than men. ${ }^{28}$ The reason why women either have or do not have more postconcussive symptoms than men is unclear, and more research is certainly needed in this area.

Most participants were employed or in school at least part time before the injury. However, they took less than 1 week off from school or work, even though the CDC stresses the importance of rest/reduced physical, thinking, or concentration activities until symptoms subside. ${ }^{1}$ Recently, the CDC developed the Acute Concussion Evaluation (ACE) to assist health care providers in teaching patients when they can return to preinjury activities. ${ }^{29}$ The first recommendation for optimal recovery from MTBI symptoms is rest. Current research also suggests that early interventions including rest and limiting physical/cognitive activities such as attending school or work will improve MTBI outcomes. ${ }^{18}$ However, there is no evidence suggesting that the ACE is routinely recommended or individually adjusted for patients not seen in a concussion clinic. This may be because of inaccurate beliefs or misconceptions related to how long symptoms last and when patients should return to work after the injury, as well as a belief that behavioral symptoms are unrelated to the brain injury. Some providers may also view physical symptoms as having a psychological origin, misinterpret motivation problems as laziness, and trivialize a patient's symptoms and their impact on the individual. ${ }^{30}$

The discharge diagnoses used in this study were concussion/CHI, MVC, head laceration, and whiplash/cervical strain. Symptom severity scores were divided into physical, thinking, sleep, and emotional categories (some participants reported having $>1$ discharge diagnosis). Those with concussion/CHI reported mild symptoms in all 4 categories, with the sleep category having the highest score. Patients with the diagnoses of MVC had symptom severity scores in the moderate range, with the highest severity in the emotional category. Those with head lacerations reported mild symptoms in all 4 categories, with the sleep category rated highest. Participants with a whiplash/cervical strain diagnosis scored higher in the thinking category (moderate) when compared with physical symptoms (mild). However, those with an MVC or whiplash/cervical strain diagnosis had higher symptom severity scores in every category when compared with subjects diagnosed with a concussion or head laceration.

Because the current literature does not separate MTBI symptoms into categories of diagnosis, it is difficult to compare findings from this study with the literature. However, there is literature discussing symptoms occurring in patients with an MTBI, and they are consistent with symptoms reported by these participants. ${ }^{2,4,14,31-33}$ Consequently, larger studies of this type are needed to identify whether there is a statistically significant relationship between diagnosis and specific MTBI symptoms. However, this pilot study identifies a gap in the MTBI literature and offers information that can be used in conducting further studies to identify MTBI symptoms related to specific diagnoses. This type of research would be especially important for staff responsible for providing discharge education to the ED patient at risk for an MTBI. 
TABLE 3

Most common symptoms occurring by discharge diagnosis

\begin{tabular}{|c|c|c|c|c|c|c|}
\hline Discharge diagnosis & All patients (n) & Male (n) & Female (n) & $\begin{array}{l}\text { No. of } \\
\text { symptoms }\end{array}$ & Most common symptoms & $\begin{array}{l}\text { Severity score } \\
\text { [mean (SD)] }\end{array}$ \\
\hline \multirow[t]{3}{*}{ Concussion/CHI } & 27 & 15 & 12 & 6 & Headache, $\mathrm{n}=17(62.9 \%)$ & $2.26(1.24)$ \\
\hline & & & & & $\begin{array}{l}\text { Difficulty remembering, } \\
\mathrm{n}=15(55.5 \%)\end{array}$ & $2.21(1.18)$ \\
\hline & & & & & Drowsiness, $\mathrm{n}=14(51.8 \%)$ & $2.33(2.4)$ \\
\hline \multirow[t]{3}{*}{ Head laceration } & 16 & 11 & 5 & 4 & Fatigue, $\mathrm{n}=5(31.2 \%)$ & $2.60(1.14)$ \\
\hline & & & & & $\begin{array}{l}\text { Sensitivity to light, } \\
\mathrm{n}=5(31.2 \%)\end{array}$ & $2.20(1.30)$ \\
\hline & & & & & Headache, $\mathrm{n}=4(25.0 \%)$ & $2.75(1.25)$ \\
\hline \multirow[t]{3}{*}{ MVC } & 12 & 4 & 8 & 0 & Headache, $\mathrm{n}=12(100 \%)$ & $3.25(1.91)$ \\
\hline & & & & & $\begin{array}{l}\text { Difficulty concentrating, } \\
\mathrm{n}=12(100 \%)\end{array}$ & $3.08(1.72)$ \\
\hline & & & & & Irritability, $\mathrm{n}=12(100 \%)$ & $3.83(1.89)$ \\
\hline \multirow[t]{3}{*}{$\begin{array}{l}\text { Whiplash and } \\
\text { cervical strain }\end{array}$} & 7 & 0 & 7 & 0 & $\begin{array}{l}\text { Feeling slowed down, } \\
\mathrm{n}=7(100 \%)\end{array}$ & $2.60(1.96)$ \\
\hline & & & & & $\begin{array}{l}\text { Feeling more emotional, } \\
\mathrm{n}=7(100 \%)\end{array}$ & $2.33(1.86)$ \\
\hline & & & & & $\begin{array}{l}\text { Difficulty remembering, } \\
\mathrm{n}=5(71.4 \%)\end{array}$ & $3.80(1.22)$ \\
\hline
\end{tabular}

Head injury education was provided to patients with a diagnosis of concussion or CHI more frequently than to patients with the other diagnoses. However, only half of the education provided was written. This is an important omission because brain-injured patients are not likely to remember instructions provided immediately after the injury. ${ }^{34}$ In addition, evidence supports giving written information with verbal reinforcement to patients who meet the diagnostic criteria for concussion. ${ }^{35}$

There were also more participants reporting MTBI symptoms than those who received head injury education in all diagnostic categories. This is another concern because head injury education is crucial to early recognition of an MTBI for prompt treatment and optimal recovery, ${ }^{16-18}$ and some evidence suggests better patient compliance with improved outcomes when providing written instructions to patients. ${ }^{34}$ Unfortunately, only one-quarter of participants diagnosed with an MVC received head injury education, and less than $10 \%$ received it in writing. This is a significant concern because MVC participants had the highest severity scores in every PCSS category, followed closely by whiplash/ cervical strain patients, who received even less head injury education. One reason participants took less than 1 week off from their routine activities despite continuing to have MTBI symptoms may be that they did not receive appropri- ate head injury education or understand the significance of following the instructions.

Participants' answers to open-ended questions showed not only changes related to the overall impact the injury had on their lives but also changes participants made as a result of the injury. Each response was categorized into 1 of 3 themes: health/functioning, psychological, and social/economic.

The health/functioning category represented physical, sensory, and neurological functions and included physical health and the ability to function in activities or roles that could be affected by health. Comments such as "I never used to have headaches and now I have them frequently" reflect this category. Comments related to neurologic/sensory difficulties include that patient found it "hard to focus, concentrate, and remember things." Other studies had similar findings. For example, Petchprapai and Winkel$\operatorname{man}^{33}$ found that headache was the most severe and frequently (30\%-60\%) reported physical complaint in their review of 35 studies; in the longitudinal studies reviewed, headache, fatigue, forgetfulness, and sleep disturbance were reported by $8 \%$ to $23 \%$ of participants 1 year after injury. Bergman and $\mathrm{Bay}^{21}$ also discovered that patients having prolonged physical complaints were likely to have disability scores $(r=0.60, P<.001)$ months after their injury that reflect how well one could function in roles one has in life. 
TABLE 4

Head injury education

\begin{tabular}{lcllrr}
$\begin{array}{l}\text { Discharge } \\
\text { diagnosis }\end{array}$ & $\mathbf{n}$ & $\begin{array}{l}\text { Received head } \\
\text { injury information }\end{array}$ & $\begin{array}{l}\text { Received verbal } \\
\text { information }\end{array}$ & $\begin{array}{l}\text { Received written } \\
\text { information }\end{array}$ & $\begin{array}{l}\text { Reported } \\
\text { symptoms }\end{array}$ \\
\hline Concussion & 27 & $20(74.0 \%)$ & $17(62.0 \%)$ & $14(51 \%)$ & $22(81.0 \%)$ \\
MVC & 12 & $3(25.0 \%)$ & $3(25.0 \%)$ & $1(8.3 \%)$ & $10(83.0 \%)$ \\
Head laceration & 11 & $5(45.4 \%)$ & $3(27.0 \%)$ & $5(0.7 \%)$ & $8(63.6 \%)$ \\
Whiplash & 7 & $2(28.5 \%)$ & $1(0.1 \%)$ & $1(0.1 \%)$ & $7(100 \%)$ \\
Other & 8 & $3(37.5 \%)$ & $3(37.5 \%)$ & $2(25 \%)$ & $8(100 \%)$
\end{tabular}

The psychological category focusing on the ability of a person to feel or to experience changes has two subthemes: neuropsychological, which includes feelings and thoughts, and neurobehavioral, which includes changes in behaviors as a result of the injury. Comments by participants such as "I feel almost worthless" and "I feel numb now" could be suggestive of being depressed and placed in this category. Such feelings were also seen in other studies. For example, Bergman and $\mathrm{Bay}^{21}$ found that the depression rate for MTBI patients was 13\%, with $9 \%$ having unresolved panic disorders 1 year after injury. In addition, Petchprapai and Winkelman ${ }^{33}$ found that depressed patients reported more frequent and severe MTBI symptoms than those who were not depressed.

The social and economic category focuses on the ability to maintain one's role in society, finances, and relationships with others. This domain is more directly impacted by the other 2 categories because headache, fatigue, and other physical symptoms, as well as feelings and thoughts that related to changes in behavior, could make it difficult for individuals with an MTBI to return to work or school. For example, even though Petchprapai and Winkelman ${ }^{33}$ found that being able to return to work was inconsistent from study to study, $84 \%$ to $88 \%$ of subjects in the studies reviewed returned to work within 1 week to 3 months after injury. In addition, almost one-third (30\%) of those who returned to work needed to modify their jobs. Indeed, it would be helpful to have a carefully constructed study using a standardized tool such as the ACE care plan to follow MTBI patients throughout their recovery to obtain more information on how the injury has affected each patient's behavior in the social and economic category because financial stress and labile emotions can affect relationships both personally and professionally and may affect one's ability to return to work. Finally, even though socioeconomic and relational outcomes after MTBI are rarely reported, they could logically affect recovery from any injury. ${ }^{33}$
This study had several limitations. First, the sample was small $(\mathrm{N}=52)$ and homogeneous. There are several reasons for the small sample size. Of the 45,218 patients whose charts were reviewed, only 702 met the inclusion criteria. The low response rate was related to being unable to send out reminder postcards because the letter of inquiry to determine whether ED patients wanted to participate in the study was sent from the Office of Research instead of by the investigator (which was a requirement to be able to conduct the study); not receiving any letters back that were undeliverable; and having to send a letter to $\mathrm{ED}$ patients asking them to go to the Internet survey link instead of sending an E-mail to them so they could click on the survey link. Second, this was a cross-sectional rather than a longitudinal study. It would be important to gather data from a larger and more ethnically diverse sample, as well as over time, to determine how soon after the injury the symptoms started, how long the symptoms were present, which symptoms were the most prevalent and severe, and how much symptoms continued to interfere with the patient's life in a larger sample. Third, even though it was possible to connect certain diagnoses with certain symptoms, there were uneven numbers of participants within each diagnosis group, making it difficult to determine whether certain symptoms were more commonly seen with specific discharge diagnoses. It would be important to examine this area in more depth. Fourth, this study was purposely limited to participants aged 18 to 28 years to obtain a sample of healthy persons without confounding medical conditions or treatments. Limiting the age of participants omitted patients aged older than 28 years who may have been equally as healthy as those included. A study with a larger age range would be important. Fifth, ED staff implementation of a program to educate patients diagnosed with a concussion or $\mathrm{CHI}$ immediately before the study began undoubtedly altered responses to the question about education received in the emergency department. However, the amount of edu- 
cation provided to all study participants was quite low. Finally, some of the participants may have had headaches, emotional problems, concentration difficulties, and so on before visiting the emergency department and completing the survey. In addition, there is limited information on how often these symptoms are reported by the general population. Therefore it is difficult to connect symptoms reported here with the MTBI event.

\section{Conclusions}

MTBIs can easily slip undetected through the emergency department because patients can present with a variety of injuries and/or subjective complaints. Most research focuses on concussions in athletes, which has brought much needed attention to the devastating effects of an MTBI. However, most athletes have a trainer or coach who is educated regarding postconcussion care. On the other hand, the general public does not have a trainer and probably does not understand the symptoms or potential consequences of an MTBI.

Finally, we need to look beyond physical complaints of MTBI patients and recognize that there may be cognitive changes as well, because symptoms vary in severity and range of deficits. Therefore nurses working in the emergency department should be more aware of the various symptoms associated with MTBI so that the number of misdiagnosed MTBI patients decreases. Because many accident patients initially seek care for their injury in the emergency department, nurses have an important role in recognizing those at risk for MTBI based on mechanism of injury and providing written MTBI information for appropriate follow-up. Increased MTBI awareness by emergency nurses will not only promote early MTBI diagnosis, resulting in prompt referral to a neuropsychologist or concussion clinic, but also give MTBI patients the best chance at optimal recovery.

\section{REFERENCES}

1. Centers for Disease Control and Prevention. TBI publications. Facts about concussion and brain injury and where to get help http:// www.cdc.gov.erl.lib.byu.edu/ncipc/tbi/TBI_Publications.htm. Accessed November 21, 2010.

2. Cassidy JD, Carroll LJ, Peloso PM, Borg J, von Holst H, Holm L, et al. WHO Collaborating Centre Task Force on Mild Traumatic Brain Injury. Incidence, risk factors and prevention of mild traumatic brain injury. Results of the WHO Collaborating Centre Task Force on Mild Traumatic Brain Injury. J Rehabil Med. 2004;43(Suppl):28-60.

3. Powell J, Ferraro JV, Dikmen SS, Temkin NR, Bell KR. Accuracy of mild traumatic brain injury diagnosis. Arch Phys Med Rehabil. 2008;89 (8):1550-5.

4. Kashluba S, Paniak C, Casey JE. Persistent symptoms associated with factors identified by the task force on mild traumatic brain injury. Clin Neuropsychol. 2008;22(2):195-208.
5. Paniak C, Reynolds S, Phillips K, Toller-Lobe G, Melnyk A, Nagy J. Patient complaints within 1 month of mild traumatic brain injury: a controlled study. Arch Clin Neuropsychol. 2002;7(4):319-34.

6. Sterr A, Herron KA, Hayward C, Montaldi D. Are mild head injuries as mild as we think? Neurobehavioral concomitants of chronic postconcussion syndrome. BMC Neurol. 2006;6:7. http://www.ncbi.nlm. nih.gov/pmc/articles/PMC1382265/pdf/1471-2377-6-7.pdf. Accessed December 19, 2010.

7. Rees RJ, Bellon ML. Post concussion syndrome ebb and flow: longitudinal effects and management. Neurorehabilitation. 2007;22(3):229-42.

8. Soo C, Tate R. Psychological treatment for anxiety in people with traumatic brain injury. Cochrane Database Syst Rev. 2007;(3):CD005239.

9. Schatz P, Pardini JE, Lovell MR, Collins MW, Podell K. Sensitivity and specificity of the ImPACT test battery for concussion in athletes. Arch Clin Neuropsychol. 2006;21(1):91-9.

10. Yang $\mathrm{C}, \mathrm{Tu} \mathrm{Y}$, Hua M, Huang $\mathrm{S}$. The association between the post concussion symptoms and clinical outcomes for patients with mild traumatic brain injury. J Trauma. 2007;62(3):657-63.

11. Fleminger S. Long-term psychiatric disorders after traumatic brain injury. Eur J Anaesthesiol Suppl. 2008;42:123-30.

12. Jakola AS, Muller K, Larsen M, Waterloo K, Romner B, Ingebrigtsen T. Five-year outcome after mild head injury: a prospective controlled study. Acta Neurol Scand. 2007;115(6):398-402.

13. Naunheim RS, Matero D, Fucetola R. Assessment of patients with mild concussion in the emergency department. J Head Trauma Rehabil. 2008;3(2):116-22.

14. Langlois JA, Marr A, Mitchko J, Jonson RL. Tracking the silent epidemic and educating the public: CDC's traumatic brain injury associated activities under the TBI act of 1996 and the children's health act of 2000. J Head Trauma Rehabil. 2005;20(3):196-204.

15. Jennett B, Teasdale G. Management of Head Injuries. Philadelphia, PA: F.A. Davis; 1981.

16. Andersson EE, Emanuelson I, Bjorklund R, Stalhammar DA. Mild traumatic brain injuries: the impact of early intervention on late sequelae. A randomized controlled trial. Acta Neurochir (Wien). 2007;149 (2):151-60.

17. Setnik L, Bazarian JJ. The characteristics of patients who do not seek medical treatment for traumatic brain injury. Brain Inj. 2007;21(1):1-9.

18. Snell DL, Surgenor LJ, Hay-Smith EJC, Siegert RJ. A systematic review of psychological treatments for mild traumatic brain injury: an update on the evidence. J Clin Exp Neuropsychol. 2009;31(1):20-38.

19. Polit D, Beck C. Essentials of Nursing Research: Appraising Evidence for Nursing Practice. 7th ed. Philadelphia, PA: Lippincott Williams \& Wilkins; 2010.

20. De Kruijk JL, Leffers P, Menheere PPCA, Meerhoff S, Rutten J, Twijnstra A. Prediction of post-traumatic complaints after mild traumatic brain injury. Early symptoms and biochemical markers. J Neurol Neurosurg Psychiatry. 2002;73(6):727-32.

21. Bergman K, Bay E. Mild traumatic brain injury/concussion: a review for ED nurses. J Emerg Nurs. 2010;36(3):221-30.

22. Kraus J, Schaffer K, Ayers K, Stenehjem J, Shen H, Afifi A. Physical complaints, medical service use, and social and employment changes following mild traumatic brain injury: a 6-month longitudinal study. J Head Trauma Rehabil. 2005;20(3):239-56.

23. Bazarian J, Blyth B, Mookerjee S, He H, McDermott M. Sex differences in outcome after mild traumatic brain injury. J Neurotrauma. 2010;27 (3):527-39. 
24. Meares S, Shores E, Taylor A, Batchelor J, Bryant R, Baguley I, et al. Mild traumatic brain injury does not predict acute post concussion syndrome. J Neurol Neurosurg Psychiatry. 2008;79(3):300-6.

25. Olff M, Langeland W, Draijer N, Gersons BP. Gender differences in post traumatic stress disorder. Psychol Bull. 2007;133(2):183-204.

26. Preiss-Farzanegan $S$, Chapman B, Wong T, Wu J, Bazarian J. The relationship between gender and postconcussion symptoms after sport-related mild traumatic brain injury. PMR. 2009;1(3):245-53.

27. Farace E, Alves W. Do women fare worse: a metaanalysis of gender differences in traumatic brain injury outcomes. J Neurosurg. 2000;93 (4):539-45.

28. Berry C, Ley E, Tillou A, Cryer G, Margulies D, Salim A. The effect of gender on patients with moderate to severe head injuries. $J$ Trauma. 2009;67:950-3

29. Centers for Disease Control and Prevention. "Heads up: Brain injury in your practice" tool kit. http://www.cdc.gov/concussion/headsup/pdf/ ACE-a.pdf. Accessed November 21, 2010.
30. Swift TL, Wilson SL. Misconceptions about brain injury among the general public and non-expert health professionals: an exploratory study. Brain Inj. 2001;15(2):149-65.

31. Centers for Disease Control and Prevention. Report to Congress on Mild Traumatic Brain Injury in the United States: Steps to Prevent a Serious Public Health Problem. Atlanta, GA: National Center for Injury Prevention and Control; 2003.

32. Mackenzie JA, McMillan TM. Knowledge of post-concussional syndrome in naive lay-people, general practitioners and people with minor traumatic brain injury. Br J Clin Psychol. 2005;44(pt 3):417-24.

33. Petchprapai N, Winkelman C. Mild traumatic brain injury: determinants and subsequent quality of life. A review of the literature. J Neurosci Nurs. 2007;39(5):260-72.

34. WeiHG, CamargoCAJr. Patient education in the emergency department. Acad Emerg Med. 2008;7(6):710-7.

35. KozakGS, YuraH. A comparison of teaching methods for ED discharge instruction after head injury. J Emerg Nurs. 1989;15(1):18-22. 